\title{
Zoledronic Acid Anhydrous
}

National Cancer Institute

\section{Source}

National Cancer Institute. Zoledronic Acid Anhydrous. NCI Thesaurus. Code C80120.

Anhydrous form of a synthetic imidazole third generation bisphosphonate analog of pyrophosphate with antiresorptive activity. Zoledronate binds to hydroxyapatite crystals in the bone matrix and inhibits farnesyl pyrophosphate (diphosphate) synthase, thereby preventing protein prenylation within the mevalonate pathway. This leads to the loss of downstream metabolites essential for osteoclast function, leading to the induction of apoptosis and eventually, osteoclast-cell death. By preventing osteoclast-mediated bone resorption, zoledronate decreases bone turnover and stabilizes the bone matrix. 